the New Zealand region. Another notable occurrence was a shock on November 1, centred in the southeast Tasman Sea, about 150 miles off the Milford Sound coast. Information is given in the bulletin on various other matters connected with the different seismographic stations and their instruments, on the research carried out on the distribution of earthquake activity in New Zealand, and on matters of general interest.

\section{War and Rheumatic Fever}

According to an article in the September issue of the Statistical Bulletin of New York, war conditions generally favour an increase of rheumatic fever in the armed forces. This was seen not only in the War of 1914-18 but also in the present conflict, in which many cases have been reported among the younger men enlisted. Susceptible individuals are usually attacked shortly after reporting for duty. About 40 per cent give a history of infection in childhood; but in a significant proportion there is no history of a previous attack. The seasonal distribution of the cases is typical, the peak being reached in the late winter and early spring. In the great majority of cases there is a history of upper respiratory infection or of scarlet fever. In the general population, however, both in the United States and in England, there has been a decline in rheumatic fever and rheumatic heart disease during a war period, the decline being attributed to decreased amount of poverty as a result of full employment, the better feeding of children, especially the increased provision of milk, and the evacuation of children from metropolitan areas.

\section{Names of Biological Colours}

Prefaced by a brief discussion, H. A. Dade (Mycological Papers No. 6: Colour Terminology in Biology. Pp. 25. Kew : Imperial Mycological Institute, 1943. 3s. 9d. net) has provided a useful dictionary list of the names of colours, cross-referenced as to synonyms, that are or may be employed, particularly as trivial names, in biology. Appended to this is a list of the words indicative of tone or texture, and two charts which give the position of the names in relation to Ridgway's "Chromatic Scale". This should prove very useful to systematic biologists, in particular those without adequate knowledge of the Classical languages, for quite frequently trivial names supposed to be indicative of colour are incorrectly applied, and sometimes so badly that they are misleading. It is to be hoped that now such an aid is available this will not occur so often in the future.

\section{Equilibrium Diagrams of Binary Alloy Systems}

"The Equilibrium Diagram of the System Aluminium-Zine" is the title of the first of a new series of publications which the Institute of Metals proposes to issue of up-to-date equilibrium diagrams of binary alloy systems. Each of the series will consist of the diagram reproduced on a large scale and based on the most reliable work in each phase-field, a table providing all the important data connected with this diagram, critical notes and a list of references. This initial publication, the work of G. V. Raynor, appears to satisfy all these points in an excellent manner, and whets one's appetite for the three others so far promised, on the copper-tin, copper-zinc and copperaluminium alloys respectively. It is available from the Institute at 4 Grosvenor Gardens, S.W.I (6d. post paid).

\section{Thoughts on Reconstruction}

THE April, June and September 1943 issues of the Krisson Bulletin contain a series of articles well designed to encourage the development of a more scientific outlook generally. The first, "A Plea for Scepticism", should encourage a more critical attitude to some of the proposals for reconstruction and particularly to political theory. It includes a useful little bibliography. In the following issue are printed eleven paragraphs of "The Universal Rights of Man" from a pamphlet by Mr. H. G. Wells to be published later. This is a development from the "Declaration of the Rights of Man". This statement of the universal rights-the right to live, protection of minors, freedom to work, right to earn money, right to possess, freedom to go about, right to know, personal liberty, freedom from violence-which are in the nature of man and cannot be changed, but could be made the basis of a new and happier way of human life, is accompanied by an appeal not to take them for granted but to work for them and to guard them. The third article, "Educated ? It is my Business", after quoting F. Sherwood Taylor's "The Century of Science", pleads for an attempt to understand our environment and to take an intelligent place in human organization.

\section{Announcements}

Dr. E. F. Armstrong has been appointed chairman of a commission appointed by the Conference of Allied Ministers of Education to report on the problems involved in the supply of scientific equipment to the occupied countries when they have been freed.

THस Council of the Institution of Naval Architects has awarded the premium of the Institution for the year 1943 to Dr. J. F. C. Conn, for his paper "Marine Propeller Blade Deflection".

A RESEARCH scholarship of the value of $\$ 400$ a year and tenable for two years has been offered by the Wrought Light Alloys Development Association to encourage and facilitate research in the application of light alloys to ship construction. The scholarship will be administered by a committee of the Institution of Naval Architects and it is hoped to make the award in September. Full particulars of entry, which closes on July 31, can be obtained from the Secretary, Institution of Naval Architects, 10 Upper Belgrave Street, London, S.W.1.

ThE Chancellor of the Exchequer has stated in a written Parliamentary reply that the Government, after considering a report from the University Grants Committee, has decided to maintain the provision for universities and colleges in the Estimates for 1944 at its existing level.

The Council of the American Astronomical Society has awarded the Annie J. Cannon Prize for women astronomers to Miss Antonia C. Maurv of Hastings, N.Y., for her distinguished work at the Harvard College Observatory in the early days of spectral classification. Miss Maury at the turn of the century devised her own system of classifying the spectra of the stars on the basis of detailed descriptions of their characteristics as obtained from high-dispersion spectra. These details have since been shown to have great significance in revealing the physical characteristics of the stars. 